\title{
The influence of food quantity on carbon and nitrogen stable isotope values in southern African spiny mice (Acomys spinosissimus)
}

\author{
G.N. Robb, ${ }^{a}$ S. Woodborne, ${ }^{\text {ab }}$ P.R. de Bruin, ${ }^{a}$ K. Medger, ${ }^{a}$ N.C. Bennett ${ }^{a}$ \\ ${ }^{a}$ Department of Zoology and Entomology, University of Pretoria, Pretoria, South Africa. \\ ${ }^{\mathrm{b}}$ iThemba LABS, Private Bag 11, WITS 2050, Gauteng, South Africa.
}

Corresponding author: Gillian Robb (e-mail: gnrobb@zoology.up.ac.za).

\begin{abstract}
Stable isotope analysis is frequently applied as a tool to examine dietary patterns in animals. However, some of the underlying assumptions associated with using this approach are increasingly being questioned. We carried out a controlled diet experiment on the southern African spiny mouse (Acomys spinosissimus Peters, 1852) to test a number of aspects relating to these assumptions and also examine the hypothesis that stable isotopes, especially $\delta^{15} \mathrm{~N}$, can be used to provide evidence of nutritional stress. We compared the $\delta^{13} \mathrm{C}$ and $\delta^{15} \mathrm{~N}$ values of livers and blood from animals that were fed ad libitum with animals undergoing a $10 \%$ reduction in food supply. Food-restricted animals showed no significant difference in $\delta^{15} \mathrm{~N}$; however, $\delta^{13} \mathrm{C}$ values of both liver and blood were depleted. Restricted animals also had a significantly lower $\mathrm{C}: \mathrm{N}$ ratio. We examined the role of lipids and found following lipid extraction that both livers and lipids still showed the same separation in carbon values. Tissue-diet discrimination values were also calculated and found to be higher for both $\Delta^{13} \mathrm{C}$ and $\Delta^{15} \mathrm{~N}$ compared with other mice species. Empirical values for discrimination rates were then compared with values calculated using an alternative method based on employing generic values and were found to be dissimilar, suggesting the use of generic values are not always appropriate. Our results highlight the need for greater understanding of the assumptions associated with using stable isotope analysis to examine diet and we suggest that studying a single species under captive conditions presents an ideal method to begin to test these hypotheses.
\end{abstract}

Keywords: Acomys spinosissimus, discrimination, food restriction, spiny mouse, stable isotope

\section{Introduction}

Stable isotope analysis has been used to answer a number of questions relating to foraging and diet; for example, quantifying reliance on different food sources (Robb et al. 2012), identifying feeding locations (Ferger et al. 2013), or determining trophic level (Woodborne et al. 2012). Most of the applications resolve interspecific issues of resource utilisation to elucidate niche separation or trophic separation. The underlying assumptions in this approach are increasingly challenged as evidence accumulates that there is a high level of complexity in the use of stable light isotopes in dietary tracing. At the centre of the emerging controversy is the chemical alteration that changes the isotopic ratio of the dietary source during the metabolic synthesis of 
one or other organ in the target organism: the diet-tissue discrimination factor (represented by $\Delta_{T S}$ ). There are several names given to this term, but essentially they all reflect the same effect, that is, the difference in isotopic value between a tissue and the diet of the organism $\left(\delta X_{T}-\delta X_{S}\right.$, where $X$ is the isotope under scrutiny, normally ${ }^{13} \mathrm{C}$ or ${ }^{15} \mathrm{~N}$, T represents the tissue, and $\mathrm{S}$ represents the dietary source). Perhaps the most pronounced influence on $\Delta_{T S}$ is the balance between the nutritional needs of the organism and the availability of key elements such as essential amino acids and protein quality available in the diet. Imbalances between dietary demand and supply of proteins affect the metabolic routing of nitrogen in particular, and this leads to interactive effects where several different protein sources are available to the organism (Robbins et al. 2002). Metabolic routing is the term used to describe the routing of different substrates following digestion, for example, carbohydrates and lipids may preferentially be used for metabolism, while proteins are routed for tissue synthesis. Roth and Hobson (2000) argue that $\Delta_{T s}$ is reduced in higher trophic levels because dietary protein closely matches the metabolic needs of the organism, while Pearson et al. (2003) suggest that the opposite effect occurs as a function of increased nitrogen content of the diet. Similarly, the relative abundance of lipids in tissues influences its bulk isotopic value because of the different metabolic pathways in lipid and protein synthesis (Post et al. 2007). Overriding all of these influences is the role of tissue turnover rates that govern the time lag between dietary intake and its isotopic manifestation in the tissues of the organism.

There have been a limited number of studies examining the effects of diet quality or quantity upon diet-tissue discrimination values; to examine the relationship between nutritional requirements and $\Delta_{T S}$. The studies have found varying results, with no clear patterns emerging. A number of studies have reported changes in the $\Delta^{15} \mathrm{~N}$. Hobson et al. (1993) suggest that animals placed under nutritional stress may show a change in the ${ }^{15} \mathrm{~N} /{ }^{14} \mathrm{~N}$ ratio. As the food is restricted the animal relies more on catabolism of endogenous protein stores, they "live on their own meat", and as a result there is an increase in ${ }^{15} \mathrm{~N}$ since consumers generally have a more ${ }^{15} \mathrm{~N}$-rich composition compared with diet sources. There is also increased recycling of metabolic amino acids and a discrimination against the heavier isotope in waste products such as urea. Despite a more ${ }^{15} \mathrm{~N}$-rich composition being observed in some studies due to nutritional stress (Hobson et al. 1993; Oelbermann and Scheu 2002; Cherel et al. 2005; McCue and Pollock 2008), other studies have shown no significant difference (Ben-David et al. 1999; Schmidt et al. 1999; Kempster et al. 2007) or even a significant depletion in ${ }^{15} \mathrm{~N}$ (Williams et al. 2007). The effects of carbon are less well understood, with most studies showing no significant change (Hobson et al. 1993; Schmidt et al. 1999; Kempster et al. 2007) and a small number showing either enriched (Oelbermann and Scheu 2002) or depleted (Williams et al. 2007; McCue and Pollock 2008) $\delta^{13} \mathrm{C}$ signatures. There is a need for further studies to better examine the effects of diet and nutritional stress upon diet-tissue discrimination, especially with regards to the level of nutritional stress involved or the effects of specific components of the diet such as proteins or carbohydrates.

Empirical evidence for variations in $\Delta_{T S}$ have been synthesised to provide simple equations that "correct" the $\delta X_{S}$ values and thus simplify and broaden the application of stable isotope dietary analysis in ecological studies. Post et al. (2007) make use of the low abundance of nitrogen in lipids and correlate $\Delta^{13} \mathrm{C}$ with $\mathrm{C}: \mathrm{N}$ ratios across a broad spectrum of organisms yielding convincing linear corrections for $\delta^{13} \mathrm{C}_{\mathrm{T}}$. 
Similarly the effect of diet quality on both $\Delta^{13} \mathrm{C}$ and the $\Delta^{15} \mathrm{~N}$ is synthesised into a generic set of relationships called the diet-dependent discrimination factor (DDDF) (Caut et al. 2009) in which the $\delta X_{\mathrm{T}}$ is used to hindcast $\Delta_{\mathrm{TS}}$. It is also suggested that $\Delta_{T S}$ is sufficiently constrained across a number of classes of organisms (such as mammals and birds) that a generic value of $\Delta_{\text {TS }}$ may be employed (Caut et al. 2009). While $\Delta_{\text {TS }}$ is assumed to be variable in the foregoing studies, Codron et al. (2012) present a sensitivity analysis that demonstrates the effect of dietary heterogeneity between species and also presumably within species (with reference to controlled mono-diet experiments) and the role of compound specific isotopic differences in the diet and metabolism of the organism.

Most of the attempts to synthesise $\Delta_{T S}$ values rely on interspecific empirical relationships without necessarily understanding the underlying metabolic mechanisms (Caut et al. 2009; Codron et al. 2012). There have been few attempts to explore the effects of metabolic mechanisms within a single species despite the obvious advantage that this has on controlling metabolic variability. In this study, we explore the effect of nutritional stress on $\Delta^{13} \mathrm{C}$ and $\Delta^{15} \mathrm{~N}$ using a controlled laboratory feeding experiment of southern African spiny mice (Acomys spinosissimus Peters, 1852). In a review of studies in 2008 examining the effect of various environmental and nutritional stressors on $\delta^{13} \mathrm{C}$ and $\delta^{15} \mathrm{~N}$, there were only eight separate studies on mammals (McCue and Pollock 2008) and only one of these was in a captive setting where diet was controlled. Although there have been subsequent studies on mammals (Deschner et al. 2012; Lee et al. 2012; Hobson and Quirk 2014; BenDavid et al. 2012), there is still a need for further experiments on a greater number of species and with varying dietary restrictions.

The African spiny mouse (henceforth spiny mouse) is a nocturnal rodent (Hoole et al. 2012) occurring in the northeastern parts of southern Africa, as well as Malawi and Tanzania (Stuart and Stuart 2007). It has a unique fur, which is thick, coarse, and spine like, and is believed to provide some protection against predators. Its diet in the wild is omnivorous, consisting of seeds and plant material, with the addition of some insects, millipedes, spiders, and snails (Stuart and Stuart 2007). In this experiment, we examine the effect of a $10 \%$ reduction in food supply to investigate the effects of moderate food restriction. Our experiment was conducted under laboratory conditions, where food intake could be measured and all other environmental factors such as temperature remained constant across all individuals. We also maintain consistent diet quality between individuals, as this may affect stable isotope values in tissues (Caut et al. 2008). The extent to which nutritional stress affects a tissue will depend on the duration of the stress, as well as the turnover rate of the tissue. In this study, we use liver, a metabolically active tissue with a rapid turnover of a number of days (DeMots et al. 2010), in which the effects of diet variability are likely to be more visible (Hobson et al. 1993). Additionally, we use a small number of blood samples as a comparison, representing a slightly longer turnover period of a few weeks (Miller et al. 2008; DeMots et al. 2010).

Only a few experiments have been carried out to test the effect of dietary stress on $\Delta^{13} \mathrm{C}$ and $\Delta{ }^{15} \mathrm{~N}$ and these have found varying and inconsistent results. However, based on the results published to date, we would predict that nutritional stress is most likely to result in changes in $\Delta^{15} \mathrm{~N}$ and to have little effect on $\Delta^{13} \mathrm{C}$. 


\section{Materials and methods}

\section{Animal collection}

Twenty-six male adult spiny mice (weighing between 18 and $26 \mathrm{~g}$ ) were trapped using Sherman live traps baited with a fish, peanut butter, and oats mixture at Goro Game Reserve $\left(22^{\circ} 58^{\prime} \mathrm{S}-22^{\circ} 57^{\prime} \mathrm{S}, 2^{\circ} 25^{\prime} \mathrm{E}-29^{\circ} 24^{\prime} \mathrm{E}\right)$ under permits granted by the Department of Environmental Affairs in Limpopo and Gauteng provinces. Traps were set out in the late afternoon and collected the next morning before sunrise. The animals were transported to the University of Pretoria where they were housed in a climate controlled room at $25^{\circ} \mathrm{C}$. They were housed individually and both shavings and bedding were provided. The animals were fed mouse pellets supplemented with occasional carrot, apple, and bird seed. The mouse pellets were made from vegetarian sources and contained $15 \%$ protein and $60 \%$ carbohydrates. Trapping took place in May and July and an acclimation period started at the end of November for a period of 40 days prior to the start of the experiment. During this acclimation period, the mice were fed on mouse pellets only and water was provided ad libitum. On the last week of the acclimation period, the food intake and body mass was determined daily for every mouse. Food intake was determined by subtracting the amount of food remaining from the original amount provided after a $24 \mathrm{~h}$ period. This was done for each mouse every $24 \mathrm{~h}$ over the week. This allowed a calculation of a mean daily food intake and mass over multiple measurements.

\section{Experimental design}

Following the acclimation period, the mice were randomly assigned to one of two feeding regimes. A sample of 14 individuals was fed ad libitum and 12 individuals were subjected to a $10 \%$ food restriction (90\% of the food intake that had been calculated during the last week of the acclimation period), based on their calculated mean individual daily food intake. The experiment ran for 8 weeks, during which the mice had access to only the mouse pellets provided, but water was available ad libitum. The animals were weighed every second day to monitor any mass loss. In the event that a mouse lost $20 \%$ of the original body mass, food would be provided ad libitum for 2 days or until the body mass recovered. The mouse pellets provided during both the acclimation period and the experimental period were from a single batch from the same manufacturer to ensure that there was isotopic and nutritional consistency in the food source both between individuals and also over the experimental period.

After the 8-week experimental period, the mice were sacrificed using an overdose of halothane. All of the restricted (12 mice) and 11 of the unrestricted mice were then fixed using 4\% paraformaldehyde (PFA) after which a liver biopsy was collected. Additionally, a blood sample was also collected from 10 of the mice (5 restricted, 5 unrestricted). It is possible that the isotopic signature of the liver samples could have been changed by the PFA. However, with regards to comparing between restricted and unrestricted samples, they were all treated identically with regards to the addition of the fixative so any effect should have been constant across the groups. The blood samples were collected prior to the addition of the PFA. 
Liver, fur, and claw samples were also collected from three ad libitum fed mice that were not fixed. Fur was removed from the lower back and 2-3 claws from the front feet. The study was conducted following guidelines set out in the "Guide to the care and use of experimental animal" (available from http://ccac.ca, accessed 20 May 2014) and with the approval of the Animal Use and Care Committee (EC008-11) at the University of Pretoria, South Africa. Animals were sacrificed as part of other research projects and for this reason liver was also sampled. All samples were then stored in the freezer prior to drying.

The four tissue types (liver, blood, fur, and claws) integrate food metabolism over different temporal periods as a result of their different turnover rates. Liver, with the fastest turnover, represents the shortest dietary time. Half-lives (the time it takes for half of the existing tissue to assimilate the isotopic signature of a new diet) in liver have been estimated from 2.8 to 7.7 days for carbon and from 3.6 to 15.1 days for nitrogen in deer mice (Peromyscus maniculatus (Wagner, 1845)) (Miller et al. 2008), laboratory mice (Mus musculus L., 1758) (Arneson et al. 2006), and white-footed mice (Peromyscus leucopus (Rafinesque, 1818)) (DeMots et al. 2010). Blood represents a slightly longer time period of a few weeks (half-lives of 14.4-22.4 days for carbon and 19.8 days for nitrogen (Miller et al 2008; DeMots et al. 2010). The stable isotope composition of fur and claws represents the diet consumed during the period in which they are grown, they then remain inert, and so the temporal record of dietary change is conserved (Bearhop et al. 2003). Half-lives in fur for carbon and nitrogen isotopes were between 65.1 and 70.2 days and between 79.9 and 85.4 days, respectively, in Sprague Dawley rats, a strain of Norway rats (Rattus norvegicus (Berkenhout, 1769)) (Kurle 2009). However, we do not know the moult cycle or growing time of fur in spiny mice, so we cannot predict precisely the dietary integration period of the fur isotopes. Based on the growth rate of claws in rats of $0.04 \mathrm{~mm} /$ day (Godwin 1959), the length of the claws used (approximately 1-1.2 $\mathrm{mm}$ ), and the difference in size between laboratory rats and spiny mice, the claw may represent a period of approximately 30-60 days. The total time period the animals were fed a single-source diet of mouse pellets, including the acclimation period, was 96 days, while the experimental food restriction period lasted 56 days. Due to the fast turnover of liver and blood, this time would have been sufficient for the new and restricted diet to be reflected. It is also likely the majority of the claw samples represent the time the mice were solely receiving mouse pellets only. However, it is possible the fur samples may incorporate some of the isotopic signal of previous diets.

\section{Stable isotope analysis and statistics}

All samples (liver, blood, fur, claws, and mouse pellets) were homogenised and oven-dried at $65+{ }^{\circ} \mathrm{C}$ for $48+\mathrm{h}$ to a constant mass. Samples were then weighed into tin cups $(0.5 \pm 0.05 \mathrm{mg})$ and run in a continuous flow isotope ratio mass spectrometer (DeltaV IRMS coupled with a Flash 1200 elemental analyser with a ConFlolV interface; all instruments from ThermoFisher, Bremen, Germany) for stable isotope analysis. Standards and blanks were interleaved with 12 unknown samples to correct the raw values. Results for stable isotope ratios are expressed using the standard $\delta$ notation as per mille (\%o). To examine the effect of lipids on the carbon values in the liver, a lipid extraction was performed. Liver samples were added to a 5 $\mathrm{mL}$ mixture of 50:50 ethanol and chloroform and placed in an ultrasonic water bath 
for 40 min. Following this, the liquid containing the lipids was carefully syringed from around the liver sample. Another $5 \mathrm{~mL}$ of ethanol and chloroform was added and the samples were placed back into the water bath for an additional 30-40 min. The liquid was then once again carefully removed from each liver sample and added to the first liquid extractions. Both the liver sample and the liquid were then oven-dried for 65+ h. The dried extracted livers and the lipids were then weighed. This allowed for the relative percentage of lipids in each of the liver samples to be estimated. The dried liver and lipid samples were then weighed into tin cups (to $0.5 \pm 0.05 \mathrm{mg}$ ) and run in the mass spectrometer to measure their carbon signatures using the same procedure as with the full liver samples.

Differences in carbon, nitrogen, and $\mathrm{C}: \mathrm{N}$ ratios between the restricted and the unrestricted animals were tested using Student's $t$ tests for both liver and blood samples. Standard ellipses and convex hulls were also calculated using the program SIAR (stable isotope analysis in R). Paired $t$ tests were used to examine the effect of lipid extraction on the $\delta^{13} \mathrm{C}$ of the livers and lipids. The percentage of lipids in the livers of restricted and unrestricted animals was also compared. Changes in mass due to the experiment were also analysed. Student's $t$ tests were used to test for differences in masses between the two groups at the start of the experiment and again at the end.

Because a single food source was provided for the spiny mice (mouse pellets), it is possible to calculate the diet-tissue isotopic discrimination. This was calculated using the samples from the three nonfixed mice for three tissue types (liver, claws, and fur); we could also estimate the value for blood from the unrestricted mice because the blood was collected prior to the fixative being used.

\section{Results}

The diet was only reduced by $10 \%$; however, despite this small diet reduction, most restricted animals lost mass compared with unrestricted animals that gained mass throughout the experimental period. At the start of the feeding experiment, there was no significant difference in the mass between restricted and unrestricted animals (Student's $t$ test, $t_{[1,21]}=0.305, p=0.764$ ). However, by the end of the feeding experiment, there was a significant difference in the final masses $\left(t_{[1,21]}=2.512, p=\right.$ 0.021) (Table 1).

Table 1. Mean mass for each feeding group (12 restricted, 11 unrestricted southern African spiny mice (Acomys spinosissimus)) at the start and end of the experimental period.

\begin{tabular}{lllll}
\hline & & \multicolumn{3}{l}{ Mean mass (g) } \\
\cline { 3 - 5 } Feeding group & Pellets & Initial & Final & Loss or gain \\
\hline Restricted & $90 \%$ of food intake & 20.2 & 19.4 & -0.7 \\
Unrestricted & Full food intake & 20.5 & 22.2 & +1.7 \\
\hline
\end{tabular}

The liver samples from the restricted animals showed a significantly depleted ${ }^{13} \mathrm{C}$ signature compared with unrestricted animals, with mean $( \pm S D)$ values of $-18.06 \% \pm$ 
$0.91 \%$ for $\delta^{13} \mathrm{C}$ and $6.46 \% \pm \pm 0.27 \%$ for $\delta^{15} \mathrm{~N}$ for restricted animals and $-15.84 \% \textrm{ } \pm$ $0.95 \%$ for $\delta^{13} \mathrm{C}$ and $6.28 \% \pm 0.27 \%$ for $\delta^{15} \mathrm{~N}$ for unrestricted animals $\left(\delta^{13} \mathrm{C}: t_{[1,21]}=\right.$ $5.76, p<0.001 ; \delta^{15} \mathrm{~N}: t_{[1,21]}=-1.55, p=0.137$ ) (Fig. 1, Tables 2 and 3 ). If the standard ellipses and convex hulls for each group are plotted using the program SIAR (Jackson et al. 2009; Parnell et al. 2010), they show distinct areas with no overlap between the two groups. There was also a significant difference in the C:N ratio of the livers $\left(t_{[1,21]}=2.27, p=0.034\right)$, with restricted animals having a lower $\mathrm{C}: \mathrm{N}$ ratio, on average. There was no relationship between body mass and liver $\delta^{13} \mathrm{C}\left(r_{[22]}\right.$ $=0.028, p=0.901)$. However, there was a relationship between the $\delta^{13} \mathrm{C}$ of livers and the difference in mass over the experimental period (measured as the difference between the first and the last masses recorded) $\left(r_{[22]}=-0.533, p=0.011\right)$ : animals that lost more mass had a more depleted carbon signature (Fig. 2).

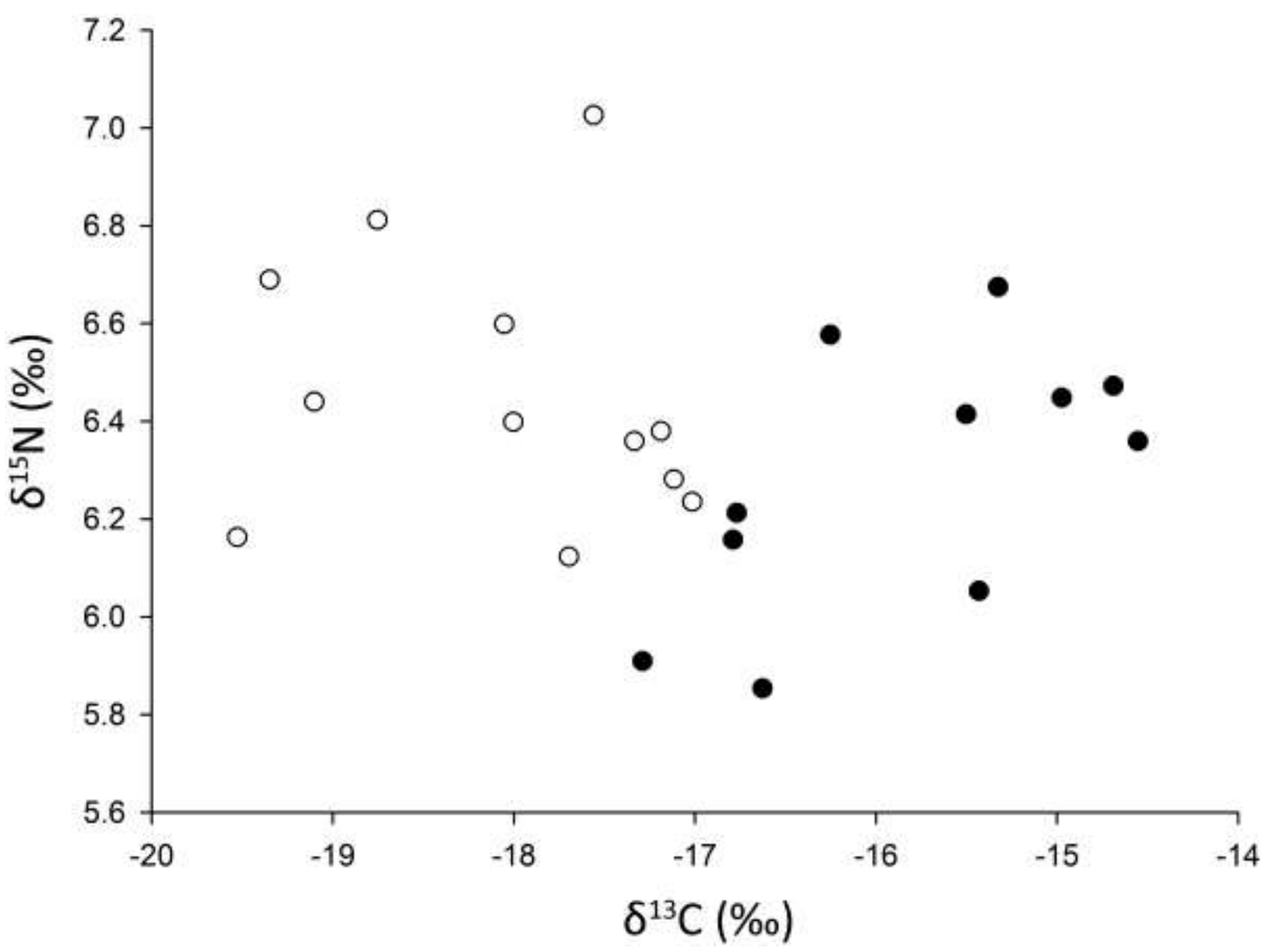

Fig. $1 . \delta^{13} \mathrm{C}$ and $\delta^{15} \mathrm{~N}$ values for livers of southern African spiny mice (Acomys spinosissimus) fed on a single-source diet of mouse pellets. Unrestricted animals received food ad libitum, while restricted animals received a $10 \%$ reduction in food intake for a period of 8 weeks. Open circles represent foodrestricted animals and solid circles represent unrestricted animals. 
Table 2. Mean and SD values for tissues from restricted and unrestricted southern African spiny mice (Acomys spinosissimus).

\begin{tabular}{|c|c|c|c|c|c|}
\hline \multirow[b]{2}{*}{ Tissue } & \multirow[b]{2}{*}{ Feeding } & \multicolumn{2}{|c|}{$\delta^{15} \mathrm{~N}(\% \circ)$} & \multicolumn{2}{|c|}{$\delta^{13} \mathrm{C}(\%)$} \\
\hline & & Mean & SD & Mean & SD \\
\hline \multirow[t]{2}{*}{ Liver } & Restricted & 6.46 & 0.27 & -18.06 & 0.91 \\
\hline & Unrestricted & 6.28 & 0.27 & -15.84 & 0.95 \\
\hline \multirow{2}{*}{ Liver (extracted lipids) } & Restricted & 6.30 & 0.58 & -17.03 & 0.90 \\
\hline & Unrestricted & 6.88 & 0.26 & -14.32 & 0.92 \\
\hline \multirow[t]{2}{*}{ Lipids } & Restricted & 5.24 & 0.67 & -21.63 & 1.45 \\
\hline & Unrestricted & 5.21 & 0.79 & -20.50 & 1.74 \\
\hline \multirow[t]{2}{*}{ Blood } & Restricted & 5.37 & 0.34 & -17.04 & 0.69 \\
\hline & Unrestricted & 5.60 & 0.48 & -15.11 & 1.00 \\
\hline
\end{tabular}

Table 3. Differences in carbon and nitrogen stable isotope values between restricted and unrestricted southern African spiny mice (Acomys spinosissimus).

\begin{tabular}{llr}
\hline & $t$ & $P$ \\
\hline$\delta^{13} \mathrm{C}$ & & \\
$\quad$ Liver & 5.76 & $<0.001$ \\
Liver with lipids extracted & 7.148 & $<0.001$ \\
Lipids & 4.241 & $<0.001$ \\
Blood & 3.53 & 0.008 \\
$\delta^{15} \mathrm{~N}$ & & \\
Liver & -1.55 & 0.137 \\
Blood & 0.71 & 0.498 \\
\hline
\end{tabular}

Note: Differences tested using Student's $t$ tests. 


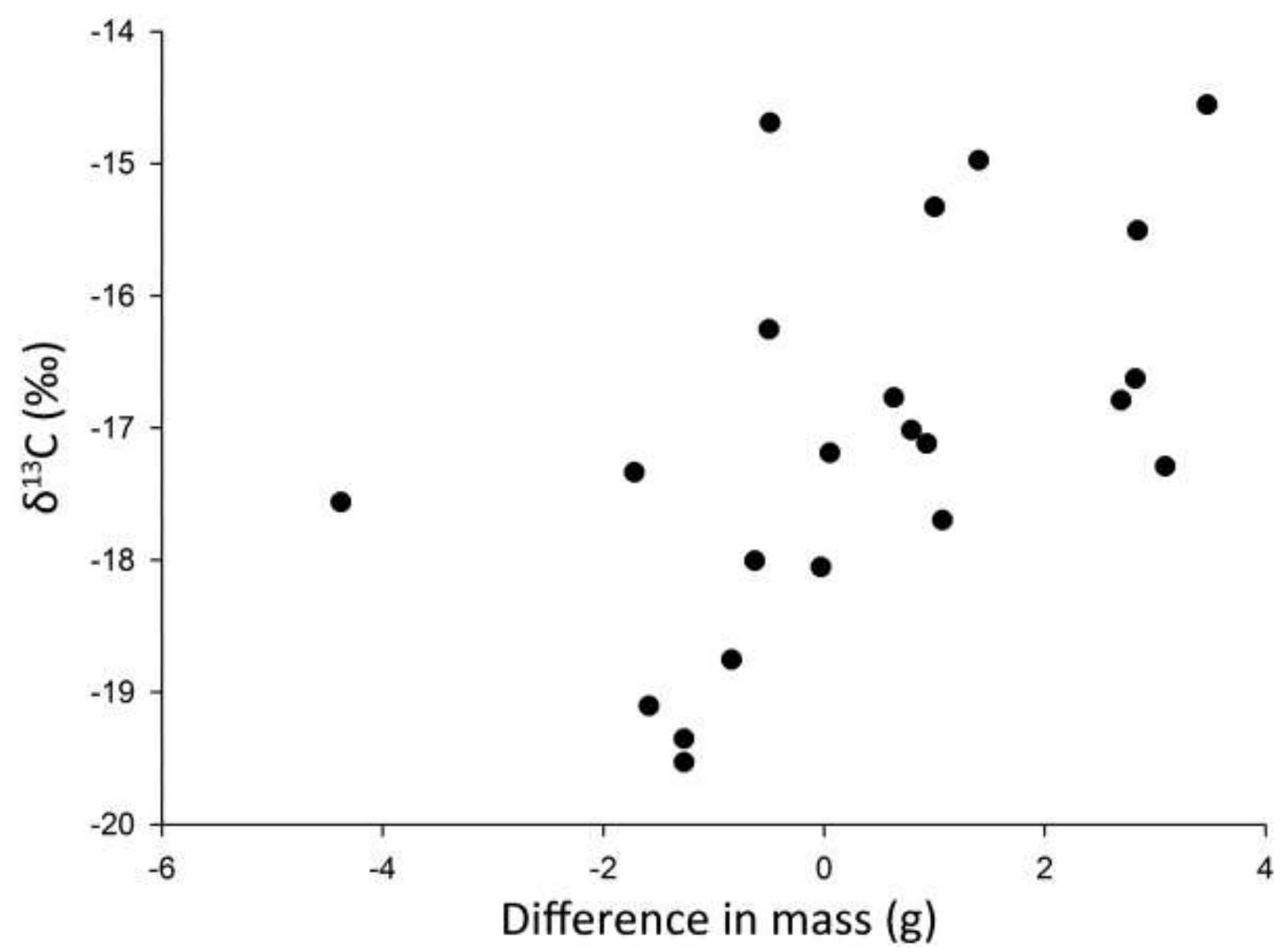

Fig. 2.Relationship between an individual's mass loss over the experimental period (measured as the difference between the mass at the start and end of the experimental period) and the value of $\delta^{13} \mathrm{C}$ in liver samples of the southern African spiny mouse (Acomys spinosissimus).

The blood samples also showed the same results with separation on the carbon isotope axis (Tables 2 and 3), with restricted animals showing a more depleted ${ }^{13} \mathrm{C}$ signature compared with unrestricted animals. Like in the liver tissues, there was a significant difference in $\delta^{13} \mathrm{C}\left(t_{[1,8]}=3.53, p=0.008\right)$ but not in $\delta^{15} \mathrm{~N}\left(t_{[1,8]}=0.71, p=\right.$ 0.498 ), although this is based on a very small sample size. Compared with the blood samples, the liver tissues were depleted in $\delta^{13} \mathrm{C}$ but enriched in $\delta^{15} \mathrm{~N}$.

Lipid extraction had a significant effect on $\delta^{13} \mathrm{C}$ of the liver (paired $t$ test, $t_{[1,21]}=$ $17.469, p<0.001$ ) but did not have a significant effect on $\delta^{15} \mathrm{~N}$ (paired $t$ test; $t_{[1,21]}=$ 1.736, $p=0.097$ ). On average, the difference in $\delta^{13} \mathrm{C}$ between the liver and the liver with lipids extracted was $1.26 \%$, while in $\delta^{15} \mathrm{~N}$ the mean difference was only $0.20 \%$. Extraction caused the $\delta^{13} \mathrm{C}$ to become more enriched, as the more depleted lipids were removed. However, following lipid extraction, the livers still showed the same separation in carbon values $\left(t_{[1,21]}=7.148, p<0.001\right)$. Additionally, the lipids showed the same pattern as the livers $\left(t_{[1,21]}=4.241, p<0.001\right)$. The results of the full liver samples were therefore not being driven by changes in the lipid content only. The $\mathrm{C}: \mathrm{N}$ ratios in the liver with the lipids extracted also show that restricted animals, on average, have a lower $\mathrm{C}: \mathrm{N}$ ratio $(4.21 \pm 0.36$, mean $\pm S D)$ than unrestricted animals $(5.28 \pm 0.65)$. 
We might predict that lipid extraction would lead to a reduction in the variance in $\delta^{13} \mathrm{C}$ values if some of the variability is a result of differential lipid contents. However, the SD value of $\delta^{13} \mathrm{C}$ of the liver samples remains the same following lipid extraction. There was considerable variation in the amount of lipids between individuals within both groups, with the percentage of lipids ranging from $7 \%$ to $19 \%$. However, there was no significant difference in the percentage of lipids in the livers from the two groups, with restricted animals having a mean of $10.8 \%(\mathrm{SD}=3.1 \%)$ and unrestricted animals having a mean of $10.1 \%(S D=2.2 \%)\left(t_{[1,21]}=0.656, p=5.19\right)$.

Previous work has suggested that $\delta^{13} \mathrm{C}$ values can be corrected using $\mathrm{C}: \mathrm{N}$ values as a proxy for lipid content (Post et al. 2007). However, we found no correlation between the $\mathrm{C}: \mathrm{N}$ values of the livers and the percentage of lipids calculated $\left(r_{[22]}=\right.$ $0.310, p=0.150$ ). We can also compare the percentage of lipids calculated from the extracted lipid masses with the mathematical approach suggested in Post et al. (2007), using the linear regression equation: \% lipids $=-30.57+10.74 \times \mathrm{C}: \mathrm{N}$. The percentages of lipids calculated using this method were higher than the percentages of lipids calculated by mass, increasing the percentage by an additional $22 \%$, on average.

A mean value for the isotope composition of the mouse pellets $\left(\delta^{13} \mathrm{C}=-20.69 \% \pm\right.$ $1.30 \%$ o, $\delta^{15} \mathrm{~N}=2.05 \% \pm \pm 0.33 \%, n=12$ ) was used to calculate discrimination values for liver, claw, and fur from the three animals that were not involved in the restriction experiment and that were not fixed, and for the blood from the five animals that were not food-restricted. (Table 4). Both $\Delta^{13} \mathrm{C}$ and $\Delta^{15} \mathrm{~N}$ were highest in fur, which also showed the greatest variation between individuals. Comparing the empirically determined $\Delta_{\text {TS }}$ values with the hindcast values using the method of Caut et al. (2009) illustrates the differences between the two methods. For liver samples in mammals (albeit a small mammal in this case), the predicted $\Delta^{13} \mathrm{C}$ value is $-0.69 \%$, which does not compare favourably with the value of $4.80 \%$ o that was measured. The measured $\Delta^{15} \mathrm{~N}$ value of $4.77 \%$ is closer but still higher than the hindcast value of $3.21 \%$. Similarly for blood, the measured versus the hindcast values, respectively, were $5.58 \%$ and $0.72 \%$ for $\Delta^{13} \mathrm{C}$ and $3.51 \%$ and $3.60 \%$ for $\Delta^{15} \mathrm{~N}$. The measured $\Delta^{13} \mathrm{C}$ and $\Delta^{15} \mathrm{~N}$ values for spiny mice are also higher when compared with other small rodents whose discrimination values have been calculated (Miller et al. 2008; Kurle 2009; DeMots et al. 2010).

Table 4. Mean and SE tissue-diet discrimination values from southern African spiny mice (Acomys spinosissimus).

\begin{tabular}{llllll}
\hline & \multicolumn{2}{l}{$\Delta^{15} \mathrm{~N}(\%)$} & & & $\Delta^{13} \mathrm{C}(\%)$ \\
\cline { 2 - 3 } \cline { 6 - 7 } Tissue & Mean & SE & & Mean & SE \\
\hline Liver & 4.77 & 0.29 & & 4.80 & 0.81 \\
Claw & 4.34 & 0.12 & & 6.37 & 0.35 \\
Fur & 7.14 & 1.18 & & 6.47 & 0.90 \\
Blood & 3.51 & 0.22 & & 5.58 & 0.45 \\
\hline
\end{tabular}




\section{Discussion}

This study revealed a significant effect of dietary stress on $\Delta^{13} \mathrm{C}$ in the order of $2.22 \%$ in liver and $1.92 \%$ in blood (the effect for nitrogen is $0.17 \%$ and $0.18 \%$, respectively, and is considered negligible relative to instrumental error). The effect on carbon isotope values between the nutritionally stressed and unstressed populations of spiny mice is in the same range as many of the interspecies variability that is used to separate dietary niches or trophic levels. The result suggests that nutritional stress may be an important influence on the variability of $\Delta^{13} \mathrm{C}$ both within species and between species, especially when comparing studies of wild animals, where dietary stress may be relatively high, with laboratory studies. The different dietary stresses also resulted in different $\mathrm{C}: \mathrm{N}$ ratios in the livers of the spiny mice with restricted animals showing a lower $\mathrm{C}: \mathrm{N}$ ratio.

Although most isotope studies on the effect of nutritional stress focus on $\Delta^{15} \mathrm{~N}$, we show that $\Delta^{13} \mathrm{C}$ is also affected, even in instances when there is no significant effect on nitrogen. Three other studies also report depletion in ${ }^{13} \mathrm{C}$ due to nutritional stress: Tufted Puffins (Fratercula cirrhata (Pallas, 1769)) (50\%-55\% reduced food intake) showed a $0.2 \% 0-0.25 \%$ depletion in $\delta^{13} \mathrm{C}$ in blood (Williams et al. 2007), King Penguins (Aptenodytes patagonicus J.F. Miller, 1778) (25 days fasting) showed a $0.71 \%$ depletion in $\delta^{13} \mathrm{C}$ in plasma in breeding adults (Cherel et al. 2005), and a springtail (order Collembola) (28 days fasting) showed a $1.1 \%$ depletion in $\delta^{13} \mathrm{C}$ in whole body samples (Haubert et al. 2005). The effect measured in this study, with only a $10 \%$ reduction in food, is exaggerated in comparison. The study on King Penguins also showed an increase in the C:N ratio and Cherel et al. (2005) suggest the depleted $\delta^{13} \mathrm{C}$ values are a result of an increase in lipid content. Lipids are known to be depleted in ${ }^{13} \mathrm{C}$ compared with proteins and carbohydrates and lipid-rich tissues have been shown to have a high C:N ratio (Matthews and Mazumder 2005). The spiny mice livers had a higher $\mathrm{C}: \mathrm{N}$ ratio than the other tissues sampled (blood, claws, and fur). However, restricted animals had a significantly lower $\mathrm{C}: \mathrm{N}$ ratio than unrestricted animals and there was no difference in the percentage of lipids in the livers between the two groups, therefore the hypothesis of an increase in lipid content causing the changes in $\delta^{13} \mathrm{C}$ in this study are not supported. This is further reinforced by the results of the lipid-extracted livers that showed the same separation in $\delta^{13} \mathrm{C}$. Williams et al. (2007) also report depleted $\delta^{13} \mathrm{C}$ with no increase in C:N ratio in Tufted Puffins. They sampled whole blood and blood cells and suggested the depleted $\delta^{13} \mathrm{C}$ values were a result of an increase in the amount of ${ }^{13} \mathrm{C}$-depleted lipids being incorporated into proteins. The correlation between difference in mass and $\delta^{13} \mathrm{C}$ in our study indicates that the changes in carbon values are associated with a negative change in body mass. Food restriction may have led to increased metabolism of exogenous or endogenous lipids to meet energetic demands, which may have resulted in the change in carbon isotopes. The reduction in body mass that we observed in our study due to the restricted feeding is relatively small compared with the loss of mass in other studies (for example, fasting King Penguins lost $28 \%$ of their initial body mass (Cherel et al. 2005) and restricted Tufted Puffins were only $60 \%$ of the mass of the unrestricted group (Williams et al. 2007). Our change in body mass of $4 \%$ compared with the initial mass of restricted spiny mice is therefore quite small, but is probably to be expected because the level of food restriction was also reduced compared with other studies. The full effects of mass change on isotopic incorporation remain unclear at present (Ben-David et al. 2012). 
It is possible that the degree of food reduction in our study (10\%) was not sufficient to detect any changes in nitrogen values. Any effect on the $\delta^{15} \mathrm{~N}$ values is likely to arise due to a limit in protein intake. The diet provided (mouse pellets) was 15\% protein and it is possible that even when consuming $10 \%$ less, this was still sufficient to meet the needs of the animal without relying on endogenous protein stores. The other explanation is that the nitrogen had not had sufficient time to turnover to reflect the restricted diet. However, the longest half-life for nitrogen in liver was 15.1 days (Arneson et al. 2006), so the restriction period of 8 weeks should have been of sufficient time to reflect the change in food.

The discrimination values that we calculated for $\Delta^{13} \mathrm{C}$ and $\Delta^{15} \mathrm{~N}$ in this study are much higher than those reported for other mouse species (Miller et al. 2008; DeMots et al. 2010), and this pattern is consistent across all of the tissues sampled. This could either be due to factors relating to the animals themselves such as metabolic routing (Pecquerie et al. 2010) or could be due to the diet provided (Kurle 2009). Carbon is predicted to show little diet-tissue discrimination, with tissue isotope ratios, on average, enriched by $1 \% 0-2 \%$ compared with that of the diet (Schoeninger and DeNiro 1984; Ambrose and DeNiro 1986). Unusually in this study, we found discrimination values for carbon to be higher than nitrogen in claws, liver, and blood tissues.

Although a single-source diet was provided, it was a bulk diet; therefore, it is possible that there was metabolic routing of certain components into the tissues and this affected the $\Delta^{13} \mathrm{C}$ and $\Delta^{15} \mathrm{~N}$ values. If carbohydrates and lipids are metabolised while the protein sources are routed to tissues to a greater extent, then the $\delta^{13} \mathrm{C}$ and $\delta^{15} \mathrm{~N}$ values of the tissues are likely to reflect a greater amount of the protein component of the diet. This could also partially explain the difference in discrimination rates between tissues, as they contain different amounts of protein and therefore will be more or less susceptible to protein routing (Perga and Grey 2010). It is also possible that the high values are related to the biology of the spiny mice and how they incorporate food into building their body tissues. For example, they have a lower resting metabolic rate than would be predicted for their body mass (Perrin and Downs 1994) and a high water efficiency, surviving periods without water by obtaining all their water demands through their food. The observed changes in $\Delta^{13} \mathrm{C}$ and $\Delta^{15} \mathrm{~N}$, as well as the change in $\mathrm{C}: \mathrm{N}$ ratios, suggest that the spiny mice mobilise energy reserves from protein storage before they access energy stored in fats. The different discrimination factors between the different tissue types may also be a result of the variable turnover times of the tissues. If the fur had not completely turned over in the experimental time, then the isotopic values for this tissue may represent some of the previous diet in addition to the laboratory diet.

The results of the controlled diet experiment for spiny mice provide a test for some of the approaches that are derived from empirical interspecies isotopic comparisons. For example, the data set enabled us to test the DDDF proposed by Caut et al. (2009). This study yields $\Delta_{\text {TS }}$ values that are very different from those that might have been calculated using the DDDF approach. It may be argued that the bulk isotopic value of the mice pellets does not reflect the protein component and hence the true $\delta^{15} \mathrm{~N}$ value of the appropriate component of the diet, thus yielding the incorrect $\Delta^{15} \mathrm{~N}_{\mathrm{TS}}$ value. While this may be true, the example of the spiny mice still 
argues against the use of a correction based on an interspecies comparative data set for an intraspecies comparison of isotopically derived diets.

We demonstrate that $\Delta^{13} \mathrm{C}$ values can be affected even when food reduction is small, rather than during starvation or greater food restriction. This highlights the need to take into consideration the different nutritional status of animals when using isotope values to examine diet. We also show the change in isotope values resulting from nutritional stress can arise solely due to a change in the quantity of diet rather any effect of quality. However, overall the difference in $\delta^{13} \mathrm{C}$ due to food restriction was still smaller than the intragroup variability. Therefore, caution is advised if only assessing a few samples to suggest evidence of nutritional stress using $\delta^{13} \mathrm{C}$ alone, without other measures such as differences in body mass or growth to support this. Further studies are required to establish if other species also demonstrate a similar result in the difference in $\delta^{13} \mathrm{C}$ due to food restriction and also to help identify the underlying mechanisms causing this change.

The results from our experiment highlight the need for greater understanding of the assumptions associated with answering questions about diet through stable isotope analysis. More knowledge is required especially with regards to the processes involved as the dietary source is assimilated into body tissues (Gannes et al. 1997; Martínez del Rio et al. 2009). Studying a single species under captive conditions where dietary input and environmental conditions can be controlled presents an ideal method to begin approaching these questions.

\section{Acknowledgements}

The research was supported by a Department of Science and Technology - National Research Foundation (DST-NRF) South African Research Chair in mammal behavioural ecology and physiology to N.C.B. and a postdoctoral research fellowship awarded to G.N.R. from the University of Pretoria and NRF. We thank Goro Nature reserve, Limpopo, for permission to trap on their land and G. Hall for assistance with running stable isotope samples and lipid extraction.

\section{References}

Ambrose SH, DeNiro MJ. 1986. The isotopic ecology of East African mammals. Oecologia 69: 395-406

Arneson LS, MacAvoy S, Basset E. 2006. Metabolic protein replacement drives tissue turnover in adult mice. Can. J. Zool. 84(7): 992-1002

Bearhop S, Furness RW, Hilton GM, Votier SC, Waldron S. 2003. A forensic approach to understanding diet and habitat use from stable isotope analysis of (avian) claw material. Funct. Ecol. 17: 270-275

Ben-David M, McColl CJ, Boonstra R, Karels TJ. 1999. ${ }^{15} \mathrm{~N}$ signatures do not reflect body condition in arctic ground squirrels. Can. J. Zool. 77(9): 1373-1378 
Ben-David M, Newsome SD, Whiteman JP. 2012. Lipid and amino acid composition influence incorporation and discrimination of ${ }^{13} \mathrm{C}$ and ${ }^{15} \mathrm{~N}$ in mink. J. Mammal. 93(2): $399-412$

Caut S, Angulo E, Courchamp F. 2008. Discrimination factors $\left(\Delta^{15} N\right.$ and $\left.\Delta^{13} C\right)$ in an omnivorous consumer: effect of diet isotopic ratio. Funct. Ecol. 22: 255-263

Caut $S$, Angulo E, Courchamp F. 2009. Variation in discrimination factors $\left(\Delta^{15} \mathrm{~N}\right.$ and $\left.\Delta^{13} \mathrm{C}\right)$ : the effect of diet isotopic values and applications for diet reconstruction. J. Appl. Ecol. 46: 443-453

Cherel Y, Hobson KA, Bailleul F, Groscolas R. 2005. Nutrition, physiology, and stable isotopes: new information from fasting and molting penguins. Ecology 86: 2281-2888

Codron D, Sponheimer M, Codron J, Newton I, Lanham JL, Clauss M. 2012. The confounding effects of source isotopic heterogeneity on consumer-diet and tissuetissue stable isotope relationships. Oecologia 169: 939-953

DeMots RL, Novak JM, Gaines KF, Gregor AJ, Romanek CS, Suluk DA. 2010. Tissue-diet discrimination factors and turnover of stable carbon and nitrogen isotopes in white-footed mice (Peromyscus leucopus) Can. J. Zool. 88(10): 961-967

Deschner T, Fuller BT, Oelze VM, Boesch C, Hublin J-J, Mundry R, Richards MP, Ortmann S, Hohmann G. 2012. Identification of energy consumption and nutritional stress by isotopic and elemental analysis of urine in bonobos (Pan paniscus) Rapid Commun. Mass Spectrom. 26: 69-77

Ferger SW, Böhning-Gaese K, Wilcke W, Oelmann Y, Schleuning M. 2013. Distinct carbon sources indicate strong differentiation between tropical forest and farmland bird communities. Oecologia 171(2): 473-486

Gannes LZ, O’Brien D, Martínez del Rio C. 1997. Stable isotopes in animal ecology: assumptions, caveats, and a call for more laboratory experiments. Ecology 78: 12711276

Godwin KO. 1959. An experimental study of nail growth. J. Nutr. 69: 121-127

D, Langel R, Scheu S, Ruess L. 2005. Effects of food quality, starvation and life stage on stable isotope fractionation in Collembola. Pedobiologia 49: 229-237

Hobson KA, Quirk TW. 2014. Effect of age and ration on diet-tissue isotopic $\left(\Delta^{13} \mathrm{C}\right.$, $\Delta^{15} \mathrm{~N}$ ) discrimination in striped skunks (Mephitis mephitis) Isot. Environ. Health Stud. 50: 300-306

Hobson KA, Alisauskas RT, Clark RG. 1993. Stable-nitrogen isotope enrichment in avian tissues due to fasting and nutritional stress: implications for isotopic analyses of diet. Condor 95: 388-394 
Hoole C, Oosthuizen MK, Chimimba CT, Bennett NC. 2012. The locomotory activity rhythm of the spiny mouse, Acomys spinosissimus from southern Africa: light entrainment and endogenous circadian rhythms. J. Zool. (Lond.) 288: 93-102

Jackson A, Inger R, Bearhop S, Parnell A. 2009. Erroneous behaviour of MixSIR, a recently published Bayesian isotope mixing model: a discussion of Moore \& Semmens (2008) Ecol. Lett. 12: E1-E5

Kempster B, Zanette L, Longstaffe FJ, MacDougall-Shackleton SA, Wingfield JC, Clinchy M. 2007. Do stable isotopes reflect nutritional stress? Results from a laboratory experiment on song sparrows. Oecologia 151: 365-371

Kurle CM. 2009. Interpreting temporal variation in omnivore foraging ecology via stable isotope modelling. Funct. Ecol. 23: 733-744

Lee TN, Buck CL, Barnes BM, O'Brien DM. 2012. A test of alternative models for increased tissue nitrogen isotope ratios during fasting in hibernating arctic ground squirrels. J. Exp. Biol. 215: 3354-3361

Martínez del Rio C, Wolf N, Carleton SA, Gannes LZ. 2009. Isotopic ecology ten years after a call for more laboratory experiments. Biol. Rev. 84: 91-111

Matthews B, Mazumder A. 2005. Temporal variation in body composition (C:N) helps explain seasonal patterns of zooplankton $\delta^{13} \mathrm{C}$. Freshw. Biol. 50: 502-515

McCue MD, Pollock ED. 2008. Stable isotopes may provide evidence for starvation in reptiles. Rapid Comm. Mass Spectrom. 22: 2307-2314

Miller JF, Millar JS, Longstaffe FJ. 2008. Carbon- and nitrogen-isotope tissue-diet discrimination and turnover rates in deer mice, Peromyscus maniculatus. Can. J. Zool. 86(7): 685-691

Oelbermann K, Scheu S. 2002. Stable isotope enrichment $\left(\delta^{15} \mathrm{~N}\right.$ and $\left.\delta^{13} \mathrm{C}\right)$ in a generalist predator (Pardosalugubris, Araneae: Lycosidae): effects of prey quality. Oecologia 130: 337-344

Parnell AC, Inger R, Bearhop S, Jackson AL. 2010. Source partitioning using stable isotopes: coping with too much variation. PLoS ONE 5: e9672

Pearson SF, Levey DJ, Greenberg CH, Martínez del Rio C. 2003. Effects of elemental composition on the incorporation of dietary nitrogen and carbon isotopic signatures in an omnivorous songbird. Oecologia 135: 516-523

Pecquerie L, Nisbet RM, Fablet R, Lorrain A, Kooijman SALM. 2010. The impact of metabolism on stable isotope dynamics: a theoretical framework. Philos. Trans. R. Soc. B Biol. Sci. 365: 3455-3481

Perga M-E, Grey J. 2010. Laboratory measures of isotope discrimination factors: comments on Caut. Angulo \& Courch $(2008,2009)$. J. Appl. Ecol. 47: 942-947 
Perrin MR, Downs CT. 1994. Comparative aspects of the thermal biology of the Cape spiny mouse, Acomys subspinosus, and the common spiny mouse, $A$. spinosissimus. Isr. J. Zool. 40: 151-160

Post DM, Layman CA, Arrington DA, Takimoto G, Quattrochi J, Montaña CG. 2007. Getting to the fat of the matter: models, methods and assumptions for dealing with lipids in stable isotope analyses. Oecologia 152: 179-189

Robb GN, Woodborne S, Bennett NC. 2012. Subterranean sympatry: an investigation into diet using stable isotope analysis. PLoS ONE 7(11): e48572

Robbins CT, Hilderbrand GV, Farley SD. 2002. Incorporating concentration dependence in stable isotope mixing models: a response to Phillips and Koch (2002) Oecologia 133: 10-13

Roth JD, Hobson KA. 2000. Stable carbon and nitrogen isotopic fractionation between diet and tissue of captive red fox: implications for dietary reconstruction. Can. J. Zool. 78(5): 848-852

Schmidt O, Scrimgeour CM, Curry JP. 1999. Carbon and nitrogen stable isotope ratios in body tissue and mucus of feeding and fasting earthworms (Lumbricus festivus) Oecologia 118: 9-15

Schoeninger MJ, DeNiro MJ. 1984. Nitrogen and carbon isotopic composition of bone collagen from marine and terrestrial animals. Geochim. Cosmochim. Acta 48: 625-639

Stuart, C., and Stuart, T. 2007. Spiny mice. In Field guide to mammals of southern Africa. Edited by G. Gordon. Struik Nature, Cape Town. p. 116.

Williams CT, Buck CL, Sears J, Kitaysky AS. 2007. Effects of nutritional restriction on nitrogen and carbon stable isotopes in growing seabirds. Oecologia 153: 11-18

Woodborne S, Huchzermeyer KDA, Govender D, Pienaar DJ, Hall G, Myburgh JG, Deacon AR, Venter J, Lubcker N. 2012. Ecosystem change and the Olifants river crocodile mass mortality events. Ecosphere 3(10 